\title{
Monitoring silt content in sediments off the Dutch Coast
}

\author{
Ronald L. Koomans ${ }^{1}$, Johan de Kok ${ }^{2}$, John de Ronde ${ }^{2}$, Marcel J.C. Rozemeijer ${ }^{3,4}$, Koos de Vries ${ }^{1}$ \\ ${ }^{1}$ Medusa Explorations BV, Verlengde Bremenweg 4, Groningen, the Netherlands, Koomans@medusa-online.com \\ ${ }^{2}$ Deltares, Postbus 177, 2600 MH Delft, The Netherlands \\ ${ }^{3}$ IMARES Wageningen UR, P.O. Box 68, 1970 AB IJmuiden, The Netherlands \\ ${ }^{4}$ Waterdienst, Rijkswaterstaat, Postbus 17, 8200 AA Lelystad
}

\begin{abstract}
Silts, present in sand extraction sites, can potentially mobilize in the water column and result in increased turbidity of the North Sea. The main knowledge gap in assessing this potential risk is the capacity to buffer silts in the sandy sediments. To assess this buffering potential, Rijkswaterstaat and Stichting LaMER started a Monitoring and evaluation program (MEP Sandmining) to monitor, amongst others, the concentration and variation of fines in the sediments off the Dutch Coast.

We monitored the concentration of fines in the sediment along 3 cross-shore tracks, ranging from $0-9 \mathrm{~km}$ off the coast, with the Medusa system and by taking sediment samples. The Medusa system results in continuous measurements of the silt content of sediments along a line, the samples have been used for validation purposes.

In the period September 2009 - Oktober 2010, 6 campaigns have been conducted. Measurements show that, although the silt content is very low $(<5 \%)$, the silt content can vary strongly on small spatial scales. Temporal variations show how the silt content along the profiles change. Comparing silt concentrations to the daily averaged wave height before the measurements, indicates that the silt contents increase with declining wave height.
\end{abstract}

\section{INTRODUCTION}

Silts, present in sand extraction sites, can potentially mobilize in the water column and result in increased turbidity of the North Sea. Computer models predict that this potential effect will not have significant consequences for ecology exploiting current quantities. However, the assumptions of these models have to be verified by a monitoring and evaluation program (MEP Sandmining) (Ellerboek e.a., 2008). The main knowledge gap in assessing this potential risk is the capacity to buffer silts in the sandy sediments. Fine silts present in the water column will settle during calm weather and will be stored in the upper decimeters of the sediment bed. During events, like a storm, these fines will go in suspension. The time scales involved in these processes and the behavior of the fine material in the upper layer of the sediment are part of the MEP of Stichting LaMER and Rijkswaterstaat. Other topics of this MEP relate to the significance of increased suspended silt and decreased amounts of algae on the growth of shellfish like Ensis directus. Apart from the sediment-based research presented in this paper, also measurements of concentrations of Suspended Particulate Matter (SPM) in the water column are conducted by taking water samples and by insitu measuring CTD, suspension concentrations and chlorophyl.

This paper focuses on monitoring changes in the content of fines in the sediments that can (re)suspend into the water column.

\section{MAPPING SEDIMENT COMPOSITION}

\section{The Medusa survey system}

Traditionally, silt content in the sediment bed is determined by taking sediment samples by (box)coring or taking grab samples. These measurements give accurate information on one spot, but spatial variation in the silt content e.g. due to the presence of small-scale morphological features as ripple structures can result in data that is not representative for large areas. Spatial variation can be mapped by taking large amounts of sediment samples, which is often too expensive.

Different hydrographic methods exist to map the variation in the composition of the sediments on the seafloor. Analysis of the acoustic signals of multi-beam and single-beam echosounders or side-scan sonar, gives high-resolution images of the composition sediments. This information helps to zone the seafloor in a classes with one type of acoustic reflection that can be related to a certain type of sediment. It is though not possible to determine absolute concentrations of silt and sand or absolute values of grain sizes of the sediment bed [du Four et al, 2005]. We propose a method that directly measures some chemical constituents of the seafloor sediments, that can directly be related to sediment composition. This relation is established by a calibration in the laboratory.

This system (named Medusa) is towed over the seafloor behind a vessel. Each second, the system measures concentrations of the natural occurring radionuclides of the seafloor. These radionuclides $\left({ }^{40} \mathrm{~K},{ }^{232} \mathrm{Th}\right.$ and $\left.{ }^{238} \mathrm{U}\right)$ are present in rocks and sediments since the origin of the earth and can be measured with a gamma spectrometer. The system measures the background radiation that is emitted by soil and sediments. Various research projects have shown how silt, sand and heavy minerals contain different concentrations and ratios of radionuclides [de Meijer, 1998]. This method is also used to measure median grain size in the field [Nederbracht and Koomans, 2005] and to map the concentration of silts in sediments [Venema and de Meijer, 2001].

The advantage of the proposed system over traditional sediment sampling, is that the detailed maps of sediment composition 
determine the spatial variation at a small scale. Moreover, it is a cost effective method for monitoring purposes.

\section{Defining the benchmark}

The specific concentrations of radionuclides for each sediment fraction (also called fingerprint) allows the measurements of the radionuclides in the sediment to be translated into maps of sediment composition. To determine fingerprint of the material that will end up in the water column as SPM, we need to 1) define the grain size fraction of the SPM; 2) define the content of SPM in sediments from the site.

\section{Grain size of SPM}

SPM has been sampled in the field and was analysed with a Malvern particle sizer [Blok, 2010]. These sediments were not pre-treated to remove organic matter or carbonates. Part of the SPM consists of organic matter. We estimated the carbonate content in the sampled material at maximum $10 \%$, the OM content in the sediment samples is $\sim 1 \%$. It is not clear how much of the $\mathrm{OM}$ is involved in the soil-water interaction. The sediment samples located on the position of the PSM samples have been analyzed with the Malvern particle sizer. Because our investigation focuses on the finest fraction of the sediments, the grains $>90 \mu \mathrm{m}$ have been removed. The sediment samples have been pre-treated to remove carbonate and organic matter.

The sieve analyses of these samples from the water column (Figure 1) show that $90 \%$ of the SPM is $<35 \mu \mathrm{m}$, with a median grain size of $16 \mu \mathrm{m}$. The analysis of the sediments show a more bimodal type grain size distribution with a slight increase around 10-20 $\mu \mathrm{m}$ (beware that due to the pre-sieving on $90 \mu \mathrm{m}$, a part of the material might be removed. The closer to $90 \mu \mathrm{m}$, the more has been removed).
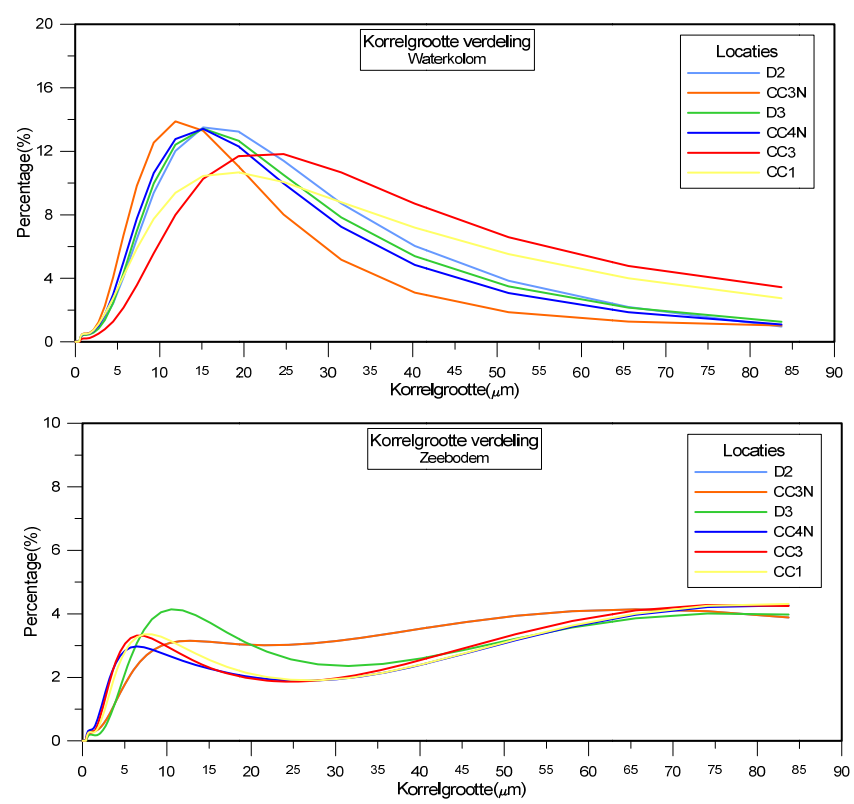

Figure 1: Sieve analysis of sediment in suspension (upper figure) and seafloor sediments. Prior to analysing, the grains $>90 \mu \mathrm{m}$ were removed by sieving
To estimate the mass of fine material that potentially suspends into the water column, we decided to map the content of the fraction $<35 \mu \mathrm{m}$ in the sediment. Therefore, the fraction $<35 \mu \mathrm{m}$ is used as a benchmark for the Medusa measurements.
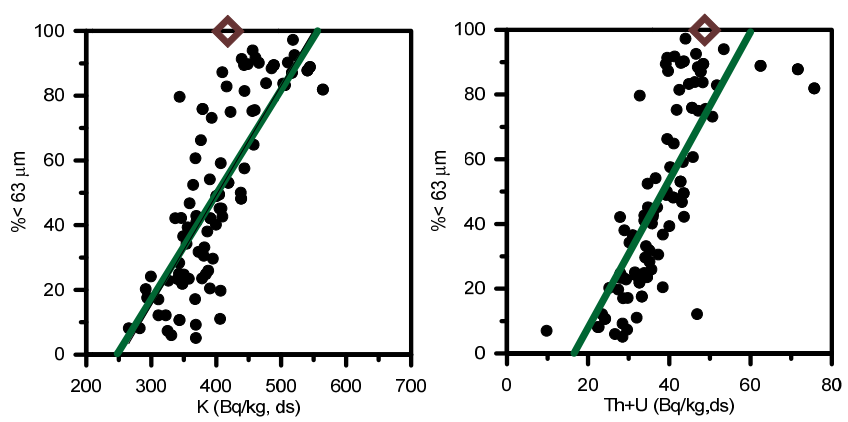

Figure 2: scatterplots of silt content $(\%<63 \mu \mathrm{m})$ vs potassium and $U+T h$ for sedimentsamples from various projects around the North Sea..The resulting numbers of clay fraction are derived from different systems (Malvern, sieving).The brown datapoint is based on measurements of SPM. Only datapoints with a silt fraction $>3 \%$ are plotted.

Measuring SPM in sediment with a content of fines $>\mathbf{3} \%$

Previous studies have shown that concentrations of K, U and Th differ between clay and sand (Figure 2). Despite the fact that the samples come from different projects and the samples were analyzed with different sieving methods, a clear correlation exists between silt fraction and radionuclide concentration. The concentration of $\mathrm{K}$ in clay is a factor of 2 larger than in sand, the concentration of the sum of $U$ and $T h$ in clay is about a factor 3 larger than in sand. The fingerprint of SPM is determined by taking SPM samples from the water column and by measuring the concentrations of radionuclides of these samples. Also the radionuclide concentration SPM correlates well with the measurements on sediment samples.

Measuring SPM in sediment with a content of fines $<\mathbf{3 \%}$

The North Sea sediments contain a low content of fines. Malvern analyses of 6 campaigns give an average fraction of 0.9 $\%( \pm 1.6)$ of sediment with a grain size $<35 \mu \mathrm{m}$. Please note that the method of analysis strongly determines the result: all samples have also been analyzed by sieving and sedigraaf. These analyses

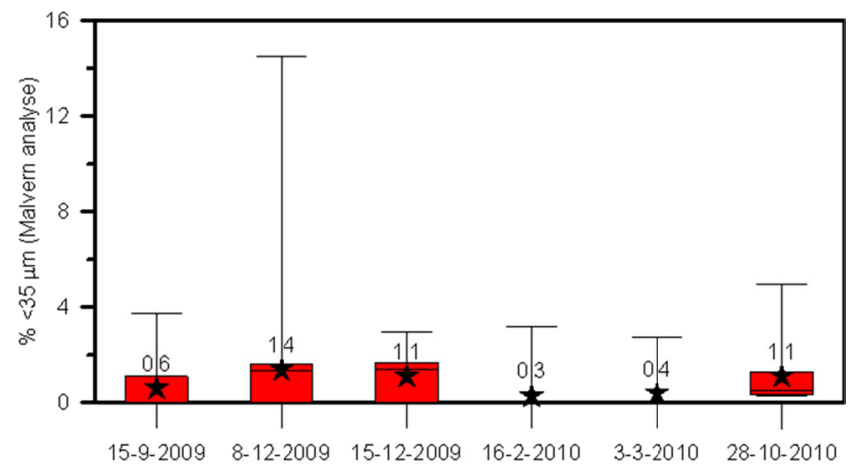

Figure 3: Box-whisker plot of the $\%<35 \mu \mathrm{m}$ of sediment samples of different campaigns, measured with the Malvern particle sizer. A star (with number) shows the average. 

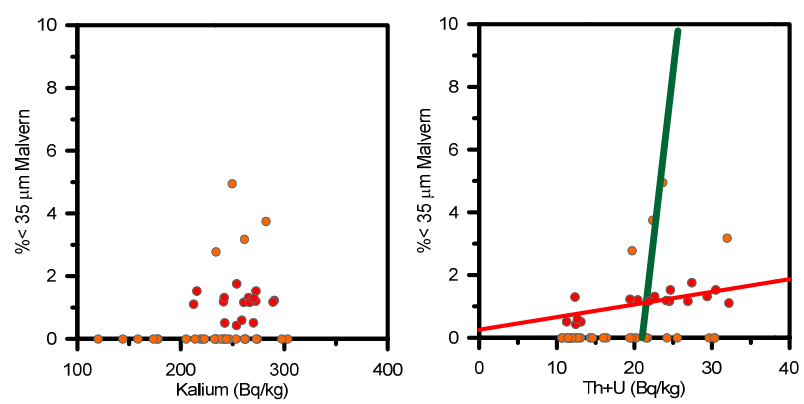

Figure 4: scatterplot of silt content $(\%<35 \mu \mathrm{m}$, measured on a Malvern) vs potassium and $U+T h$ for sediment samples taken during the project. The red line present a linear fit of the samples with a silt content $>0.3 \%$ and $<3 \%$. The green line presents the fingerprint of SPM (see Figure 2).

give an average fraction of $1.6 \%( \pm 1.4)$ of sediment with a grain size $<35 \mu \mathrm{m}$.

The sediment samples have a very low silt content, close to the lower limit of detection of the 'traditional' sample techniques and probably close to the fingerprinting method of the Medusa system. The concentrations of $\mathrm{K}$ and the summed concentration of $\mathrm{U}+\mathrm{Th}$ are compared with Malvern analysis in Figure 4.

A large number of samples have a fraction $<35 \mu \mathrm{m}$, which is smaller than $0.3 \%$. These samples (orange colored in the graph) are probably below detection limit and are omitted from the analysis. The red line gives a linear fit of the samples with silts measured above detection limit. Figure 4 does not show a correlation between the silt fraction and the concentration $\mathrm{K}$, but does show a correlation between the silt fraction and the concentration of U+Th. However, this correlation deviates strongly from the fingerprint of SPM.

An additional analysis of the chemical composition of these samples shows that heavy minerals are present in the sediments. The concentration of these heavy minerals (with an increased concentration of $\mathrm{U}+\mathrm{Th}$ ) correlate strongly with the silt fraction in the sediments. The correlation between the silt fraction and $\mathrm{U}+\mathrm{Th}$ is therefore the result of a cross correlation between $\mathrm{U}+\mathrm{Th}$, heavy minerals and grain size.

To conclude the fingerprint analyses, we have shown that the concentration of $\mathrm{U}+\mathrm{Th}$ is enriched in SPM and that the concentration of $\mathrm{U}+\mathrm{Th}$ is enriched in heavy minerals. For SPM fractions $>3 \%$, the enrichment in $\mathrm{U}+\mathrm{Th}$ due to heavy minerals is negligible and U+Th can be used as a direct proxy for SPM content. For SPM fractions $<3 \%$, the determination of absolute concentrations of SPM content is possible with an adapted calibration. Due to their higher density, sediment transport of heavy minerals is smaller than sediment transport rates of quartz and clays. In the region of study, outside the breaker bar system, sorting of heavy minerals is a very slow process [Koomans and de Meijer, 2004] and we can assume that within the time span of our study the content of heavy minerals is constant. With this assumption, changes in the content of U+Th can be attributed to changes in SPM content of the sediments. With this approach, we have a system for quantitatively monitoring the change in the content of fines in the sediment.

\section{MEASUREMENT PROGRAM}

The program focused on two line measurements, with a length of $8 \mathrm{~km}$, perpendicular to the coastline (A and $\mathrm{C}$ track in Figure 5) and two lines, with a length of $10 \mathrm{~km}$, parallel to the coastline (B and D track in Figure 5). The site was located near Bergen aan Zee. In total 6 campaigns were conducted in the period of September 2009-Oktober 2010.

\section{RESULTS}

Figure 6 shows the results of track C. The average silt content is $0.6 \%$ with an increased zone of $1.1 \%$ around $500 \mathrm{~m}$ from the coast. Sample location CC2 is locater in this elevated zone.

The change in silt content with respect to the T0 measurement of September 2009 is visible in Figure 6. Almost all measurements show a positive deviation from the Sieptember measurements, only the region 2000-3500 m shows lower a lower silt content in T3 and T4 measurements. The total deviation is between -2.5 and $5 \%$.

\section{DISCUSSION}

The main goal of the study is to understand the buffering of SPM in the sediment. Since we expect that wave action is an important driving force in the mobilization of the fine material, wave heights of the periods before the measurements have been analyzed. As a first exploration, we compared the average wave height 2 days before the measurement with the averaged silt content in the sediment (Figure 7).

The comparison (Figure 7) shows how in the T1 and T2 measurements, silt content is $4-8 \%$ higher than in the T0 measurement. Prior to these campaigns, the wave height is 100 $120 \mathrm{~cm}$, which is $80 \mathrm{~cm}$ lower than the wave height prior to the T0 campaign. This small dataset indicates that after a short period with lower wave height, the silt content in the sediment is higher.

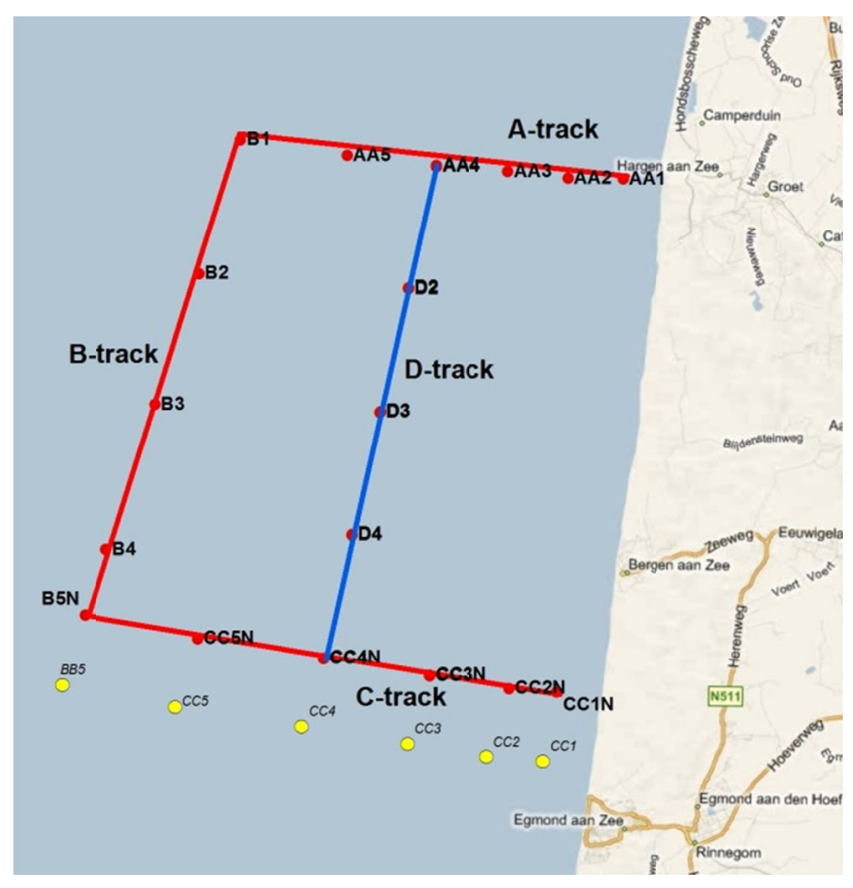

Figure 5: overview of the measured tracks. 

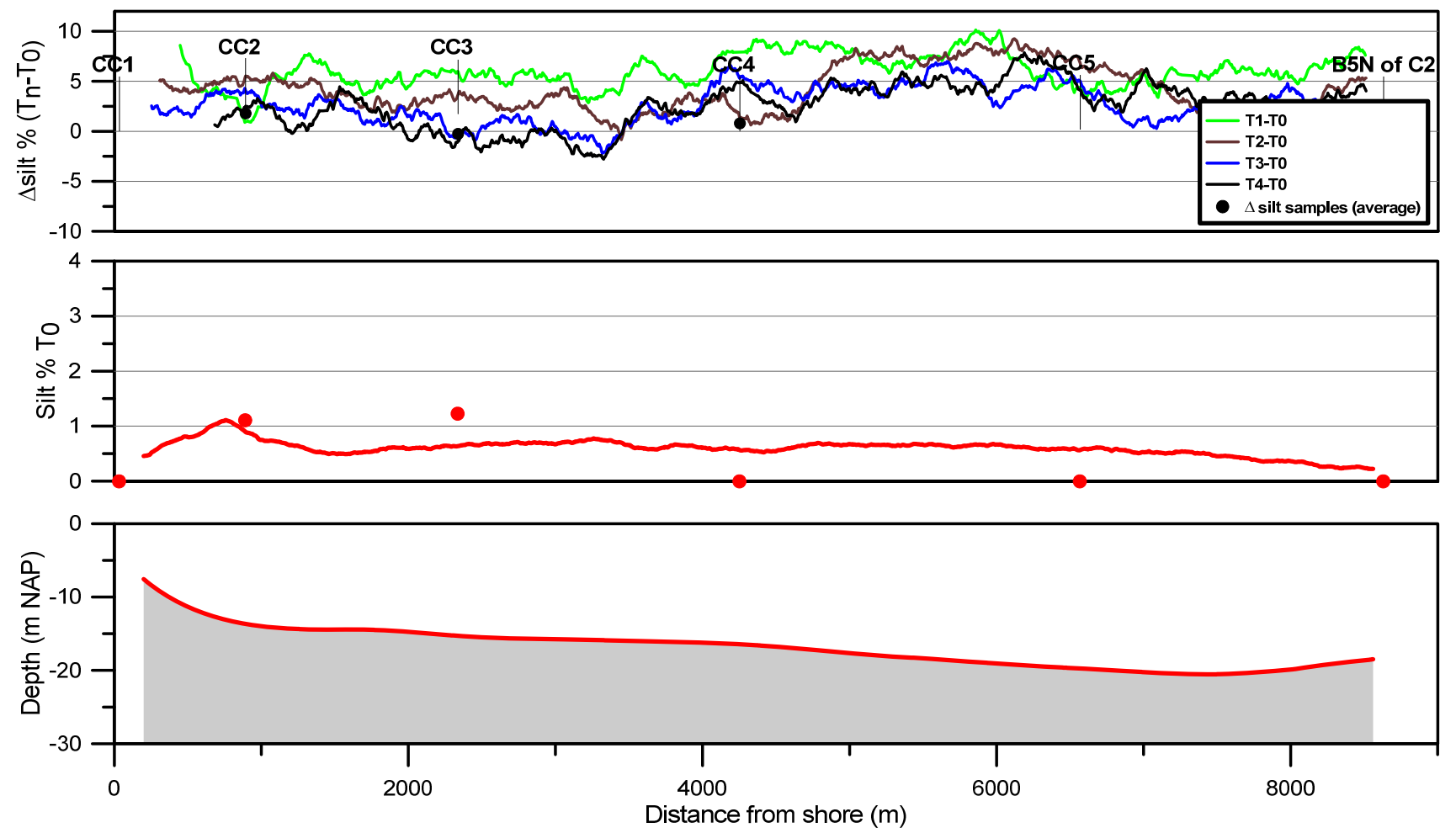

Figure 6: Result of the monitoring of track $C$, with the change in silt fraction, silt content in the T0 measurement and water depth..

\section{CONCLUSIONS}

An intensive study on the grain size distribution and chemical composition of SPM and fine sediments samples from the North Sea, show that the Medusa system is a powerful tool for mapping fine sediments in situ. For silt concentrations $>3 \%$ a direct relation between the concentration of radionuclides and silt content can be used; for silt concentrations $<3 \%$ the change in the content of fine silts can be mapped.

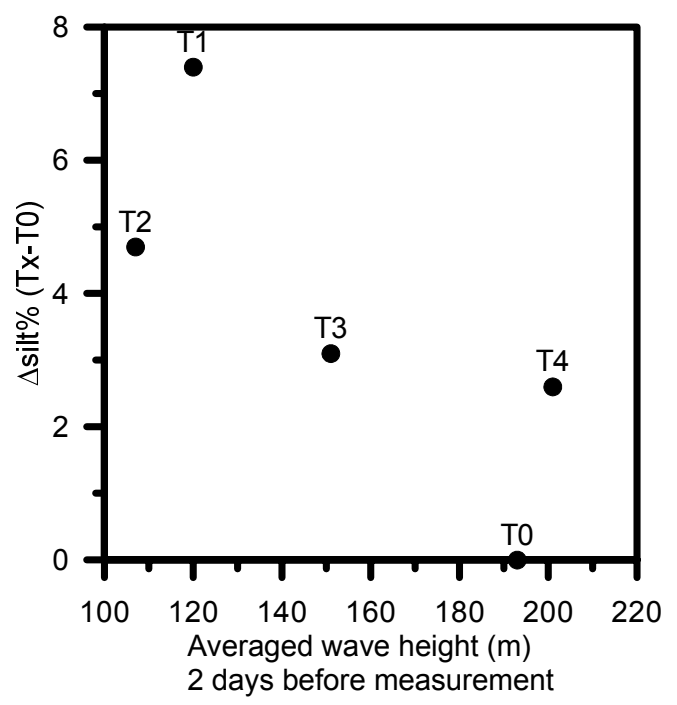

Figure 7: Change in average silt content as function of averaged wave height before the measurement.
A two year monitoring of fine sediments off the coast near Bergen shows that the silt content of sediment changes in space and in time. A first assessment of wave height information and the measured content of fines in the sediment shows how a decrease in wave height, results in a higher silt content in the sediment.

\section{ACKNOWLEDGEMENT}

This project was initiated and funded by Stichting LaMER and Rijkswaterstaat.

\section{REFERENCES}

Blok, B. 2010. Meetvis, Medusa metingen van september en december 2009. 1201293-000, Deltares, Delft.

Du Four, I., Deleu, S., Darras, I., Roche, M., Koomans, R., \& Van Lancker, V. (2005). Comparison between different seabed classification techniques and validation with sediment samples on two shallow-water dumping sites (Belgian continental shelf). Shallow Survey 2005 4th International conference on high resolution surveys in shallow water, Plymouth, Devon, UK.

Koomans, R.L. and de Meijer, R.J. 2004. Density gradation in crossshore sediment transport. Coastal Engineering, 51: 1105-1115.

de Meijer, R. J. (1998). "Heavy minerals: from 'Edelstein' to Einstein." Journal of Geochemical Exploration 62(1-3): 81-103

Ellerbroek, G., M.J.C. Rozemeijer, J.M. de Kok, J. de Ronde (2008) Evaluatieprogramma MER winning suppletiezand Noordzee 2008-2012. RWS Noord-Holland 16 juli 2008

Nederbracht, G. and R. L. Koomans (2005). Nourishment of the slope of a tidal channel: from experiment to practice. Coastal Dynamics, Barcelona, Spain, ASCE.

Venema, L. B. and R. J. de Meijer (2001). "Natural radionuclides as tracers of the dispersal of dredge spoil dumped at sea." Journal of Environmental Radioactivity 55(3): 221-239. 